\title{
Quantificação de Danos Causados pela Giberela em Cereais de Inverno, na Safra 2000, em Passo Fundo, RS*
}

\author{
Edivan Panisson, Erlei M. Reis \& Walter Boller \\ Faculdade de Agronomia e Medicina Veterinária, Universidade de Passo Fundo, CEP 99001-970, Cx. Postal 601, \\ Passo Fundo, RS, e-mail: erleireis@uol.com.br
}

(Aceito para publicação em 08/10/2002)

Autor para correspondência: Erlei Melo Reis

PANISSON, E., REIS, E.M. \& BOLLER, W. Quantificação de danos causados pela Giberela em cereais de inverno, na safra 2000, em Passo Fundo, RS. Fitopatologia Brasileira 28:189-192. 2003.

\begin{abstract}
RESUMO
Nas últimas safras, epidemias de Giberela, causadas pelo fungo Gibberella zeae, têm sido observadas em todas as regiões de clima quente e úmido aonde os cereais de inverno são cultivados. Com o objetivo de determinar os danos quantitativos causados pela doença em cereais de inverno foi conduzido um experimento em Passo Fundo RS, utilizando uma cultivar de centeio (Secale cereale), uma cultivar de triticale (Triticum x secale), três cultivares de cevada (Hordeum vulgare) e seis cultivares de trigo (Triticum aestivum). As determinações foram feitas em parcelas experimentais de $75 \mathrm{~m}^{2}$, manejadas de acordo com as recomendações técnicas das culturas, sem a aplicação de fungicidas para o controle da Giberela. A

metodologia empregada permitiu determinar os danos de maneira semelhante a uma lavoura comercial colhida mecanicamente. No centeio, o dano foi de 43,9\% (1537 kg.ha-1), no triticale de 0,1\% (5 kg.ha- $\left.{ }^{-1}\right)$, na cevada variou de 3,5 a $14,5 \%$, com média de $8,3 \%\left(252 \mathrm{~kg} \cdot \mathrm{ha}^{-1}\right)$ e no trigo variou de 4,2 a 25,9\%, com média de 17,5\% (640 kg.ha-1 $)$. Podese concluir, em face do montante de danos causados, que medidas de controle desta doença devem ser desenvolvidas a fim de minimizar os danos. Em relação a cevada são necessários mais estudos relacionados com a epidemiologia e com a quantificação de danos.

Palavras-chave adicionais: Gibberella zeae, centeio, cevada, trigo.

\section{ABSTRACT}

Assessment of damage caused by head blight in winter cereal crops in the 2000 season, in Passo Fundo county, RS

In the last crop seasons, epidemics of head blight (Gibberella zeae) were observed in many crop regions throughout the world. Head blight is considered a floral disease because it affects plants from the anthesis to the soft dough stage. The damage caused by the disease is both quantitative and qualitatively. The objective of this research was to quantify the damage caused by head blight to winter cereal crops. The experiment was carried out in Passo Fundo, in the State of Rio Grande do Sul, with one cultivar of rye (Secale cereale),

one of triticale (Triticum x secale), three of barley (Hordeum vulgare), and six of wheat (Triticum aestivum). Spikes were sampled from $75 \mathrm{~m}^{2}$-experimental plots managed without fungicides. The methodology of damage quantification simulated real losses from commercial fields harvested with combines. Overall, the head blight damage reached $43,9 \%\left(1537 \mathrm{~kg} \cdot \mathrm{ha}^{-1}\right)$ on rye, $0,1 \%\left(5 \mathrm{~kg} \cdot \mathrm{ha}^{-1}\right)$ on triticale, $8,3 \%\left(252 \mathrm{~kg} \cdot \mathrm{ha}^{-1}\right)$ on barley, and $17,5 \%\left(640 \mathrm{~kg} \cdot \mathrm{ha}^{-1}\right)$ on wheat. More studies on the disease epidemiology and disease damage are needed to evaluate the viability of chemical control for head blight on barley.
\end{abstract}

Nos últimos anos, epidemias severas de giberela [Gibberella zeae (Schw.) Petch.] em cereais de inverno têm sido observadas com frequiência em todas as regiões do mundo (Mauler-Macnik \& Zahn, 1994, Parry et al., 1995; McMullen et al., 1997). Em geral, as epidemias ocorrem esporadicamente, associadas com períodos prolongados de molhamento das espigas, desde o início da antese até a maturação fisiológica (Andersen, 1948; Sutton, 1982; Reis, 1988; Parry et al., 1995). Mauler-Machnik \& Zahn (1994) apontam como a principal causa para o aumento da intensidade da doença o sistema plantio direto e secundariamente a rotação de culturas com hospedeiros suscetíveis, o pouco avanço no desenvolvimento de cultivares com resistência genética à doença, além da baixa eficácia do controle químico em condições de campo.

*Parte da dissertação de Mestrado do primeiro autor. Universidade de Passo Fundo, Passo Fundo, RS (2001).
A giberela é uma doença de infecção floral (Arthur, 1891; Andersen, 1948; Strange et al., 1974; Reis, 1988) causada pelo fungo G. zeae cuja forma anamórfica é Fusarium graminearum Schwabe. O fungo apresenta habilidade de competição saprofítica, sobrevivendo em restos culturais de diversas espécies vegetais (Sutton, 1982), estando presente em todas as regiões do mundo onde os cereais são cultivados (Parry et al., 1995).

Os danos causados pela doença podem ser quantitativos e qualitativos (Wiese, 1987; Reis, 1988; Bai \& Shaner, 1994; Mauler-Machnik \& Zahn, 1994; Parry et al., 1995), porém comumente estes envolvem reduções no rendimento de grãos, no peso hectolítrico e com a produção de micotoxinas. Danos secundários são atribuídos a redução do teor de proteínas dos grãos (Mauler-Machnik \& Zahn, 1994; Mesterházy \& Bartók, 1996) e a redução do poder germinativo e do vigor das sementes (Tuite et al., 1990). 
O objetivo do presente trabalho foi determinar os danos quantitativos causados por G. zeae em cereais de inverno, na safra de 2000, em Passo Fundo, RS.

Os danos causados pela doença foram quantificados em uma cultivar de centeio (Secale cereale L.) BR 1, em uma cultivar de triticale (Triticum $x$ secale W.) BRS 148, em três cultivares de cevada (Hordeum vulgare L.) BR 2; EMBRAPA 127 e MN 682 e em sete cultivares de trigo (Triticum aestivum L.) BR 23; BRS 49; BRS 119; BRS 120; BRS 179; BRS 194; Fundacep 30.

As amostras de espigas foram coletadas em parcelas de $75 \mathrm{~m}^{2}$ na área Experimental da Faculdade de Agronomia e Medicina Veterinária da Universidade de Passo Fundo, localizada em Passo Fundo a uma latitude de $28^{\circ} 15^{\prime}$ Sul, longitude de $52^{\circ} 24^{\prime}$ e altitude de $684 \mathrm{~m}$ acima do nível do mar. De acordo com a classificação de Köppen o clima da região é do tipo fundamental úmido e variedade específica de subtropical, durante o ciclo dos cereais de inverno (junho a novembro) a temperatura mínima média é de $11,1^{\circ} \mathrm{C}$, a temperatura média é de $21,3{ }^{\circ} \mathrm{C}$, a temperatura máxima média é de $32,1^{\circ} \mathrm{C}$, a umidade relativa média é de $72 \%$, e a precipitação pluvial é de 963,8 mm (Cunha, 2001).

Em todas as cultivares os tratos culturais foram realizados de acordo com as recomendações técnicas das respectivas culturas, inclusive a aplicação de fungicidas antes do espigamento para o controle de doenças foliares.

Foram coletadas as espigas em área de $0,25 \mathrm{~m}^{2}$ para cada cultivar empregando-se quatro repetições. Coletou-se o centeio, o triticale e o trigo no estádio de desenvolvimento 88 da escala fenológica de Zadocks et al. (1974) e a cevada no estádio 90. No laboratório separou-se e contou-se o número de espigas sadias (assintomáticas) e doentes (sintomáticas). Para a cevada, o trigo e o triticale considerou-se doente a espiga apresentando duas ou mais espiguetas com sintomas de branqueamento. Para o centeio, havendo a maioria das espigas doentes, consideraram-se infetadas aquelas que apresentavam cinco ou mais espiguetas com sintomas. Em seguida, as espigas foram secas em estufa a uma temperatura de 55 ${ }^{\circ} \mathrm{C}$ por $48 \mathrm{~h}$. Posteriormente, as amostras foram processadas separadamente em trilhadora de espigas.

Para a determinação dos danos empregou-se metodologia proposta por Reis (1966), cujos procedimentos foram: a) pesagem dos grãos das espigas sadias e doentes, separadamente; b) determinação do rendimento potencial (RP) através da divisão do peso total de grãos das espigas sadias pelo número de espigas sadias e multiplicando-se esse valor pelo número total de espigas; c) cálculo do rendimento real (RR) através da soma do peso dos grãos das espigas sadias e do peso dos grãos das espigas doentes. Os danos (D) foram estimados subtraindo-se o RP pelo RR (Reis, 1986). A trilhadora de espigas utilizada removeu os grãos giberelados e chochos da mesma forma que uma colheita mecanizada o faz em uma lavoura.

Entre os cereais de inverno, o centeio foi o que apresentou maior suscetibilidade à doença. Esta condição pode estar relacionada com o tamanho das anteras, as maiores entre as espécies testadas. Provavelmente esse fator possa oferecer uma maior área de impacto para os esporos depositarem-se sobre as anteras. Deve-se salientar que praticamente todas as espigas desta espécie apresentavam sintomas. Os danos causados pela doença foram de 1.537 kg.ha- ${ }^{-1}(43,9 \%)$, mostrando o potencial destrutivo da doença (Tabela 1).

No triticale, embora suscetível e com incidência de $84 \%$, não se detectou redução no rendimento de grãos causados pela doença. Isso pode estar relacionado com a baixa severidade e que, provavelmente, com duas ou três espiguetas gibereladas/espiga não ocorram danos; deve haver uma compensação de modo que as espiguetas sadias produzam grãos com maior peso. Além disso, a floração pode ter ocorrido em período com condições climáticas desfavoráveis ao desenvolvimento da doença, caracterizando um escape à infecção.

Na cevada, observou-se grande número de espiguetas infetadas, isoladamente, e na maioria dos casos, a infecção resultou na não formação da cariopse. O dano médio detectado foi de $252 \mathrm{~kg} \cdot$ ha $^{-1}$, equivalente a $8,3 \%$. O dano mais elevado ocorreu na cultivar MN 682, enquanto que o menor, foi detectado na 'Embrapa 127'. A cultivar MN 682 apresentou a maior incidência, não indicando todavia que seja o mais suscetível, já que a antese ocorreu em períodos distintos e a forma de infecção nesta espécie vegetal ainda não foi esclarecida.

Não se encontrou nenhuma referência sobre a quantificação de danos no centeio, na cevada e no triticale, no Brasil. Deve-se salientar que, além dos danos quantitativos, a doença pode ter efeitos sobre a qualidade dos grãos e das sementes, principalmente pela produção de toxinas. Por isso, trabalhos neste sentido devem ser conduzidos principalmente em cevada, onde problemas causados pelas toxinas são conhecidos (McMullen et al., 1997).

Como em muitos outros patossistemas faltam dados confiáveis sobre a quantificação de danos para a giberela em cereais de inverno. Parry et al. (1995) salientam que infelizmente, em muitos trabalhos com esses objetivos, os autores não fazem menção da metodologia utilizada para determiná-los.

$\mathrm{Na}$ China em anos com epidemias severas (50 a $100 \%$ de incidência) reduções no rendimento de 10 a $40 \%$ têm sido detectadas (Bai \& Shaner, 1994). Nos Estados Unidos, danos de aproximadamente $4 \%$ foram estimados nas safras, no início da década de 90 (McMullen et al., 1997).

A incidência da doença nas cultivares utilizadas foi alta (Tabela 1). Provavelmente na região norte do estado do Rio Grande do Sul, a maior epidemia da doença tenha sido observada nesta safra. As diferenças de incidência entre as cultivares (Tabela 1) não indicam que elas sejam mais ou menos resistentes à doença, uma vez que a floração ocorreu em períodos distintos.

No Brasil as quantificações de dano foram realizadas entre os anos de 1984 e 1994, na Embrapa-Trigo em Passo Fundo, utilizando diversas cultivares recomendadas e 
Quantificação de danos causados pela giberela em cereais de inverno...

TABELA 1 - Danos causados por Gibberella zeae em cereais de inverno. Passo Fundo, RS, 2000

\begin{tabular}{|c|c|c|c|c|c|c|c|c|c|c|c|}
\hline \multirow{2}{*}{ Cultura } & \multirow{2}{*}{ Cultivar } & \multicolumn{3}{|c|}{ Espigas $\left(n^{0} \cdot m^{-2}\right)$} & \multirow{2}{*}{$\begin{array}{c}\text { Incidência } \\
(\%)\end{array}$} & \multicolumn{2}{|c|}{ Peso dos grãos $(\mathrm{g})^{*}$} & \multicolumn{2}{|c|}{$\begin{array}{c}\text { Rendimento } \\
\left(\text { kg.ha }^{-1}\right)\end{array}$} & \multicolumn{2}{|c|}{ Dano } \\
\hline & & Sadia & Doente & Total & & Sadia & Doente & RP & $\overline{\mathbf{R R}}$ & kg.ha $^{-1}$ & $\%$ \\
\hline Centeio & BR 1 & 38 & 358 & 396 & 90,4 & 33,6 & 163,0 & 3504 & 1966 & 1537 & 43,9 \\
\hline Triticale & BRS 148 & 60 & 323 & 383 & 84,3 & 57,6 & 309,7 & 3678 & 3673 & 5 & 0,1 \\
\hline Cevada & Embrapa 127 & 237 & 256 & 493 & 51,9 & 125,6 & 126,5 & 2612 & 2521 & 91 & 3,5 \\
\hline Cevada & BR 2 & 259 & 337 & 596 & 56,5 & 160,6 & 184,0 & 3695 & 3446 & 250 & 6,8 \\
\hline Cevada & MN 682 & 156 & 385 & 541 & 71,2 & 82,8 & 162,8 & 2871 & 2456 & 416 & 14,5 \\
\hline Média & & & & & & & & 3059 & 2808 & 252 & 8,3 \\
\hline Trigo & BRS 119 & 57 & 276 & 333 & 82,9 & 58,8 & 270,2 & 3432 & 3290 & 143 & 4,2 \\
\hline Trigo & BR 23 & 70 & 373 & 443 & 84,2 & 59,3 & 281,3 & 3752 & 3406 & 346 & 9,2 \\
\hline Trigo & BRS 179 & 138 & 212 & 350 & 60,6 & 134,4 & 167,5 & 3410 & 3020 & 390 & 11,4 \\
\hline Trigo & BRS 49 & 86 & 233 & 319 & 73,0 & 93,3 & 174,2 & 3460 & 2674 & 785 & 22,7 \\
\hline Trigo & BRS 120 & 97 & 310 & 407 & 76,2 & 95,7 & 208,2 & 4014 & 3039 & 975 & 24,3 \\
\hline Trigo & BRS 194 & 61 & 249 & 310 & 80,3 & 43,6 & 122,5 & 2216 & 1661 & 555 & 25,1 \\
\hline Trigo & Fundacep 30 & 97 & 374 & 471 & 79,4 & 102,2 & 265,4 & 4964 & 3676 & 1288 & 25,9 \\
\hline Média & & & & & & & & 3607 & 2967 & 640 & 17,5 \\
\hline
\end{tabular}

* Peso dos grãos correspondentes ao número de espigas trilhadas.

linhagens em fase final de experimentação. Os danos quantificados variaram de $0,4 \%$ a $14 \%$, com média de $5,4 \%$ (Reis et al., 1996).

As cultivares de trigo que apresentaram menor dano foram o BRS 119, o BR 23 e o BRS 179, com valores inferiores a $11,4 \%$. As demais cultivares apresentaram danos superiores a $22 \%$. O dano médio das sete cultivares foi de $640 \mathrm{~kg} \cdot \mathrm{ha}^{-1}$ ou 17,5\% (Tabela 1). Os danos encontrados nesta safra foram três vezes superiores aos obtidos por Reis, et al. (1996). Salientando-se que o trabalho conduzido por esses últimos autores foi feito antes da generalização do sistema plantio direto. $\mathrm{O}$ aumento da intensidade e dos danos da giberela constatados no Brasil confirma os relatos de MaulerMacnik \& Zahn (1994), Parry et al. (1995) e McMullen et al. (1997) que observaram aumento da frequiência e da intensidade devido a manutenção dos restos culturais sobre o solo.

Como os danos causados pela doença não superavam o custo de controle com fungicida, não se recomendava o controle químico da doença (Reis et al., 1996). Por exemplo, a aplicação de um fungicida triazol custa em média U\$ 24,00/ ha. Portanto, no momento considerando-se o preço de comercialização do trigo de U\$ 105,00 e os danos de 229 kg.ha-1, constata-se que a perda iguala ao valor de uma aplicação de fungicida. Infere-se que nas condições atuais de danos pode ser justificável o controle químico da giberela, embora com eficiência de controle de 50 a $75 \%$. Salienta-se, também, que o fungicida aplicado no controle da giberela pode controlar juntamente outras doenças da cultura oferecendo maior garantia de retorno econômico dessa prática de controle.

\section{AGRADECIMENTOS}

Os autores agradecem a Bayer S.A. pelo suporte financeiro dado a execução deste trabalho.

\section{REFERÊNCIAS BIBLIOGRÁFICAS}

ANDERSEN, A.L. The development of Gibberella zeae headblight of wheat. Phytopathology 38:595-611.1948.

ARTHUR, J.C. Wheat Scab. Indiana Agricultural Experimental 36:192-232.1891.

BAI, G. \& SHANER, G. Scab of wheat: prospects for control. Plant Disease 78:760-766.1994.

CUNHA, G.R. Clima de Passo Fundo - Normais climatológicas. Capturado em 02 de janeiro de 2001. Online. http:// www.cnpt.embrapa.br

MAULER-MACHNIK, A. \& ZAHN, K. Ear fusarioses in wheat new findings on their epidemiology and control with Folicur (tebuconazole). Pflanzenschutz-Nachrichten Bayer 47:129-155.1994.

McMULLEN, M., JONES, R. \& GALLENBERG, D. Scab of wheat and barley: a re-emerging disease of devastating impact. Plant Disease 81:1340-1348.1997.

MESTERHAZY, A. \& BARTÓK, T. Control of Fusarium head blight of wheat by fungicides and its effect on the toxin contamination of the grains. Pflanzenschutz-Nachrichten Bayer 49:181-198.1996.

PARRY, D.W., JENKINSON, P. \& McLEOD, L. Fusarium ear blight (scab) in small grain cereals - a review. Plant Pathology 44:207238.1995.

REIS, E.M. Metodologia para determinação de perdas causadas em trigo por Gibberella zeae. Fitopatologia Brasileira 11:951-955.1986. REIS, E.M. Doenças do trigo III; giberela. 2a ed. São Paulo. 1988. REIS, E.M., BLUM, M.M.C., CASA, R.T. \& MEDEIROS, C.A. Grain losses caused by the infection of wheat heads by Gibberella zeae in southern Brazil, from 1984 to 1994. Summa Phytopathologica 22:134-137.1996.

STRANGE, R.N., MAJER, J.R. \& SMITH H. The isolation and identification of choline and betaine as the two major components in anthers and wheat germ that stimulate Fusarium graminearum in vitro. Physiological Plant Pathology 4:277-290.1974. 


\section{E. Panisson et al.}

SUTTON, J.C. Epidemiology of wheat head blight and maize ear rot caused by Fusarium graminearum. Canadian Journal of Plant Pathology 4:195-209.1982.

TUITE, J., SHANER, G. \& EVERSON R.J. Wheat scab in soft red winter wheat in Indiana in 1986 and its relation to some quality measurements. Plant Disease 74:959-962.1990.

ZADOCKS, J.C., CHANG, T.T. \& KONZAC, C.F. A decimal code for the growth stages of cereals. Weed Research 14:415-421. 1974. 